\title{
A dynamic model of entrepreneurship with borrowing constraints: theory and evidence
}

\author{
Francisco J. Buera
}

Received: 28 January 2008 / Accepted: 4 March 2009 / Published online: 5 April 2009

(C) The Author(s) 2009. This article is published with open access at Springerlink.com

\begin{abstract}
Does wealth beget wealth and entrepreneurship, or is entrepreneurship mainly determined by an individual's ability? A large literature studies the relationship between wealth and entry to entrepreneurship to inform this question. This paper shows that in a dynamic model, the existence of financial constraints to the creation of businesses implies a non-monotonic relationship between wealth and entry into entrepreneurship: the probability of becoming an entrepreneur as a function of wealth is increasing for low wealth levels — as predicted by standard static models-but it is decreasing for higher wealth levels. U.S. data are used to study the qualitative and quantitative predictions of the dynamic model. The welfare costs of borrowing constraints are found to be significant, around $6 \%$ of lifetime consumption, and are mainly due to undercapitalized entrepreneurs (intensive margin), rather than to able people not starting businesses (extensive margin).
\end{abstract}

Keywords Entrepreneurship - Occupational choice $\cdot$ Financial constraints · Savings behavior

JEL Classification D91 $\cdot$ D92 $\cdot$ G00 $\cdot$ J22 $\cdot$ J23

\section{Introduction}

Does wealth beget wealth and entrepreneurship, or is entrepreneurship mainly determined by an individual's ability? A large empirical literature has studied the importance

I thank Fernando Alvarez, Gary Becker, Pierre-André Chiappori, Mariacristina De Nardi, Xavier Gine, James Heckman, Boyan Jovanovic, Robert Townsend, and Iván Werning for valuable comments and suggestions. I also benefited from comments of participants at various seminars.

F. J. Buera $(\bowtie)$

UCLA, Los Angeles, USA

e-mail: fjbuera@econ.ucla.edu 
of financial frictions to entrepreneurship. An important focus of this literature is the study and interpretation of the observed relationship between entry into entrepreneurship and wealth. ${ }^{1}$ A positive relationship between entry into entrepreneurship and wealth is often seen as evidence in favor of borrowing constraints. Indeed, this is the basic implication of a simple static model (e.g., Evans and Jovanovic 1989).

Nevertheless, as argued by many authors, it is important to understand the endogenous determination of wealth to be able to interpret this correlation. For example, people with no entrepreneurial ability tend to save less and are also less likely to start businesses. This paper studies the savings decision of an individual that faces the choice to become an entrepreneur, but is financially constrained, to guide the interpretation of the data.

The analysis of the dynamic model provides three main predictions that are compared to data: (1) individuals who eventually become entrepreneurs have higher savings rates than individuals who expect to remain workers; (2) the growth rate of consumption of new entrepreneurs is higher than that of workers and old entrepreneurs; (3) the probability of becoming an entrepreneur as a function of wealth is increasing for low wealth levels - as predicted by standard static models-but it is decreasing for higher wealth levels.

The first prediction summarizes nicely the essential ingredient of the model: workers can save up to overcome borrowing constraints to become entrepreneurs. As discussed above, depending on their relative skills, some workers choose to never become entrepreneurs, either because it is not productively efficient or because the savings required to overcome the constraints require too large a sacrifice. Others find that becoming an entrepreneur will have a large enough surplus and consequently save more. The second prediction follows from the fact that new entrepreneurs are still constrained with respect to their capital level and consequently have a higher marginal product of capital than the market interest rate. The last prediction follows from the fact that wealth and entrepreneurship are jointly determined in the model. For low wealth levels, entry into entrepreneurship increases with wealth because it relaxes the borrowing constraint, just as predicted by standard static models. For high wealth levels, however, entry into entrepreneurship and wealth become negatively related. This negative relationship reflects the fact that over time individuals with high entrepreneurial skills are selected out of the pool of workers and that this selection effect increases with wealth. Intuitively, if an individual is rich and still works for a wage, then it is unlikely that he has a high entrepreneurial skill. This prediction contrasts sharply with the conventional wisdom in the empirical literature on borrowing constraints and entrepreneurship.

The analysis of the model thus suggests that using data on saving rates, consumption growth, and the transition into entrepreneurship as a function of wealth would allow the estimation of the model. This is done by minimizing the distance between the statistics describing the behavior of saving rates of entrepreneurs and the dynamics

\footnotetext{
1 Of particular relevance for this paper is the work by Evans and Leighton (1989), Evans and Jovanovic (1989), Holtz-Eakin et al. (1994), Quadrini (1999), Gentry and Hubbard (2001), and Hurst and Lusardi (2004) for the U.S. and Paulson and Townsend (2004) for Thailand.
} 
of entrepreneurship in the U.S. data and the same statistics from the simulated model. In other words, the model is estimated by a simulated method of moments procedure as described by Gourieroux and Monfort (1996).

At the estimated parameter values, welfare costs of borrowing constraints are substantial. Consumption must be increased by $6 \%$ to make individuals indifferent between the economy with borrowing constraints and the one with perfect capital markets. At the same time, poverty traps tend not to be important for the U.S. economy. This is because the entrepreneurial technology is estimated to have sharply decreasing returns to the variable factors that need to be financed. ${ }^{2}$ Welfare costs arise mainly because it take a long time for extremely able entrepreneurs to operate their businesses at their unconstrained scale. Most profitable individuals eventually get to start businesses in the estimated model.

\subsection{Literature review}

A large empirical literature has studied the importance of financial frictions to entrepreneurship. An important focus of this literature is the study and interpretation of the observed relationship between entry into entrepreneurship and wealth. ${ }^{3}$ A positive relationship between entry into entrepreneurship and wealth is often seen as evidence in favor of borrowing constraints. Indeed, this is the basic implication of a simple static model (e.g., Evans and Jovanovic 1989). Nevertheless, as argued by many authors, it is important to understand the endogenous determination of wealth to be able to interpret this correlation. For example, people with no entrepreneurial ability tend to save less and are also less likely to start businesses. The observed correlation between entry and wealth partially reflects the endogenous determination of wealth as opposed to a "causal" effect of liquidity. ${ }^{4}$ This paper directly addresses this question by modeling the endogenous determination of wealth and entrepreneurship. Interestingly enough, novel predictions arise from the analysis of a dynamic model of wealth determination and entrepreneurship.

Related, it is important to note that the model is able to fit the relationship between the transition into business ownership and wealth, especially the fact that "only for households at the top of the wealth distribution is there a strong and positive relationship between household wealth and business entry" (see Hurst and Lusardi 2004). Through the lens of the dynamic model, the data is consistent with borrowing constraints playing a substantial role on the dynamics of entrepreneurship, although

\footnotetext{
2 Note that this could be either because the span of control of (mainly small) businesses in the data is low or because they operate labor-intensive technologies.

3 Of particular relevance for this paper is the work by Evans and Leighton (1989), Evans and Jovanovic (1989), Holtz-Eakin et al. (1994), Quadrini (1999), Gentry and Hubbard (2001), and Hurst and Lusardi (2004) for the U.S. and Paulson and Townsend (2004) for Thailand.

4 See Holtz-Eakin et al. (1994) for an early discussion of how the endogeneity of wealth may affect the interpretation of the entry and wealth relationship. In a recent paper, Hurst and Lusardi (2004) present evidence against wealth being a good indicator of liquidity for individuals becoming entrepreneurs.
} 
the effect of borrowing constraints on the creation of businesses appears to be transitory. ${ }^{5}$

This paper is also motivated by and complements a recent literature that studies the quantitative implications of models of occupational choice and borrowing constraints. Numerical solutions of related models are studied by Quadrini (2000) and Cagetti and Nardi (2005). These authors have shown that models featuring entrepreneurship and financial frictions are important to explain the observed wealth distribution in the U.S economy. In a similar vein, Cagetti and Nardi (2004), Li (2002), and Meh (forthcoming) quantify the effect of various policies in models featuring entrepreneurs and credit constraints for the U.S. economy. Buera (2007) provides a theoretical characterization of savings behavior in a continuous time version of this class of models. Hopenhayn and Vereshchagina (2007) study the discrete time analog. This paper complements this literature by providing an analytical characterization of entrepreneurial entry dynamics in this class of models.

The rest of the paper is organized as follows. Section 2 describes the individual's dynamic occupational choice problem. Section 3 presents the implications of the model for the average relationship between wealth and the likelihood of a transition to entrepreneurship. Section 4 confronts the predictions of the model and measures the welfare costs of borrowing constraints by estimating the model using U.S. data.

\section{The model economy ${ }^{6}$}

The model is set in continuous time. Households are endowed with entrepreneurial ability, $e$, and initial wealth, $a_{0}$. Throughout their life, they have the option to work for a wage, $w$, and invest their wealth at a constant interest rate, $r$, or to work and invest in an individual specific technology with productivity $e$, i.e., to become entrepreneurs. If households decide to be entrepreneurs they must devote all their labor endowment to run their businesses, i.e. occupations are indivisible. This captures a fundamental nonconvexity: households are more productive specializing in one activity. Households are only allowed to borrow up to a fraction of their wealth.

\subsection{Preferences}

Agents' preferences over consumption profiles are represented by the time separable utility function

$$
U(c)=\int_{0}^{\infty} e^{-\rho t} u(c(t)) d t
$$

\footnotetext{
${ }^{5}$ Hurst and Lusardi (2004) also show that the average starting capital of small businesses is small. The estimated model is also consistent with this observation as a large fraction of entrants do so with low wealth levels, and therefore, at a small scale. Looking again through the lens of the model, this fact implies that a substantial fraction of the entrants have a large relative ability as entrepreneurs, i.e., large ability as entrepreneurs relative to their ability as workers.

6 This section draws heavily from Buera (2007).
} 
where $t$ is the age of the individual and $\rho$ is the rate of time preference. The utility function over consumption, $u(c)$, is strictly increasing and strictly concave.

The infinite horizon is a convenient analytical assumption. The theory should be understood as describing the life-cycle of an individual. Under this interpretation, $\rho=\rho^{*}+p$, where $\rho^{*}$ is the rate of time preferences and $p$ is the constant rate at which agents die. When studying the quantitative implications of the theory, a discrete time version of the model with a finite horizon will be simulated and estimated.

\subsection{Resource constraints and technologies}

Agents start their lives with wealth $a_{0}$. At any time $t \geq 0$, their wealth, $a(t)$, evolves according to the following law of motion

$$
\dot{a}(t)=y(a(t))-c(t) \quad t \geq 0,
$$

where $y(a(t))$ is the income of the agent with wealth $a(t)$, and $\dot{a}$ refers to $\frac{\partial a(t)}{\partial t}{ }^{7}$ The shape of the income function depends on occupational choices as follows.

If agents choose to be wage earners, they will sell their labor endowment for a wage $w$ and invest their wealth at a rate of return $r$. In this case, their income $y(a)$ is

$$
y^{W}(a)=w+r a
$$

where $r a$ is the return on their wealth $a$. I refer to $w$ as the wage, but it should be understood that wages are individual-specific. Formally, $w=\bar{w} l$, where $l$ are the efficiency units that an individual can supply and $\bar{w}$ is the price of an efficiency unit of labor.

If individuals run a business they must devote their entire labor endowment to operate the business. Their revenue is given by the function, $f(e, k)$, where $e$ is the agent-specific ability and $k$ is the amount of capital invested in the business. ${ }^{8} f(e, k)$ is assumed to be strictly increasing in both arguments, homogeneous of degree 1 , and strictly concave in capital, $f_{e}(e, k)>0, f_{k}(e, k)>0, f_{k k}(e, k)<0$, for $e, k>0$. Inada conditions are assumed to hold, $\lim _{k \rightarrow 0} f_{k}(e, k)=\infty$ and $\lim _{k \rightarrow \infty} f_{k}(e, k)=$ 0 , for $e, k>0$. A higher entrepreneurial ability is associated with a higher marginal product of capital, $f_{e k}(e, k)>0$, also $f(0, k)=0$ and $\lim _{e \rightarrow \infty} f(e, k)=\infty$, for $e$, $k>0$.

The amount of capital that agents can invest in their businesses is constrained by their wealth. To focus the analysis on the interaction between individual savings and

\footnotetext{
7 For simplicity of exposition, I drop time as an argument of the different functions.

8 The production function should be interpreted as the reduced form of a more general technology requiring capital and labor,
}

$$
f(e, k)=\max _{n} \tilde{f}(e, k, n)-\bar{w} n,
$$

where $n$ are the efficiency units of labor employed and $\bar{w}$ is the price of an efficiency unit of labor. When calibrating the model and when discussing the predictions of the model for technologies with different capital intensities, the more general notation will be used. 
occupational choice, I choose a simple specification of borrowing constraints. In particular, I assume that the value of an individual's business assets, $k$, must be less than or equal to a multiple of their wealth, $k \leq \lambda a, \lambda \geq 1$. If wealth exceeds the amount required to finance the desired business assets, the remaining wealth is invested at the rate $r$.

Therefore, the income of an entrepreneur solves the following static profit maximization problem:

$$
y^{E}(e, a)=\max _{k \leq \lambda a}\{f(e, k)+r(a-k)\} .
$$

Note that the scale of the business equals the individual's wealth, $a$, as long as wealth is lower than the unconstrained scale of the business, $k_{u}(e)$. The unconstrained scale is the solution to the unconstrained profit maximization problem, i.e.,

$$
k_{u}(e)=\arg \max _{k}\{f(e, k)-r k\} .
$$

The assumptions imposed above imply that this function is well-defined for all $e$ and strictly increasing.

\subsection{Consumer's problem}

Agents choose profiles for consumption, $c(t)$, wealth, $a(t)$, occupational choice, and business assets, $k(t)$, to solve

$$
\begin{aligned}
& \max _{c(t), a(t), k(t) \geq 0} \int_{0}^{\infty} e^{-\rho t} u(c(t)) d t \\
& \text { s.t. } \\
& \dot{a}(t)=y(a(t))-c(t) \\
& y(e, a(t))=\max \left\{y^{E}(e, a(t)), y^{W}(a(t))\right\} .
\end{aligned}
$$

As is implicitly recognized in the statement of the problem, the occupational decision is a static one. That is, given current wealth, $a$, agents choose to be entrepreneurs if their income as entrepreneurs, $y^{E}(e, a)$, exceeds their income as wage earners, $y^{W}(a)$, i.e., $y^{E}(e, a) \geq y^{W}(a)$.

This can be expressed as a simple policy function. Define $\underline{e}$ to be the ability at which individuals are just indifferent between being wage earners and being entrepreneurs conditional on being able to borrow freely at the interest rate $r .{ }^{9}$ Able individuals

$9 \underline{e}$ solves

$$
\max _{k} f(\underline{e}, k)-r k=w .
$$

The left hand side of this equation is well defined, increasing, continuous, takes the value zero for $e=0$ and goes to infinity as $e$ goes to infinity. 
(individuals with ability above $\underline{e}$ ) decide to be entrepreneurs if their current wealth is higher than the threshold wealth $\underline{a}(e), a \geq \underline{a}(e)$, where $\underline{a}(e)$ solves

$$
f(e, \lambda \underline{a}(e))=w+r \lambda \underline{a}(e) .
$$

Intuitively, agents of a given ability choose to become entrepreneurs if they are wealthy enough to run their businesses at a profitable scale. Alternatively, agents of a given wealth $a$ choose to become entrepreneurs if their ability is high enough. Both ability and resources determine the occupational decision.

Given the optimal static decision, the dynamic program is equivalent to a standard capital-accumulation problem subject to a production function of the form

$$
y(e, a)= \begin{cases}w+r a & \text { if } a \in[0, \underline{a}(e)) \\ f(e, \lambda a)-(\lambda-1) r a & \text { if } a \in\left[\underline{a}(e), k_{u}(e) / \lambda\right) . \\ f\left(e, k_{u}(e)\right)+r\left(a-k_{u}(e)\right) & \text { if } a \in\left[k_{u}(e) / \lambda, \infty\right)\end{cases}
$$

This technology is given by the upper envelope of the "wage earner technology," $y^{W}(a)$, and the "entrepreneurial technology," $y^{W}(e, a) . k 1$ describes these technologies. Notice that this production function is not concave. The return to capital increases if individuals invest more than $\underline{a}(e)$. This simple observation implies that the consumption growth of individuals becoming entrepreneurs jumps upwards as their wealth increases above $\underline{a}(e)$.

I conclude this section by noting that:

Remark 1 The model is homogeneous of degree 1 in $(a, w, e)$.

Exploiting this property, I normalize all the variables in the model by the wage. When studying the behavior of entrepreneurs in the data, this also suggests that wealth to wage ratios are the relevant measure of resources available to individuals and that the relevant notion of entrepreneurial ability to the model is relative ability, i.e., entrepreneurial ability relative to the ability as a worker $e / w$.

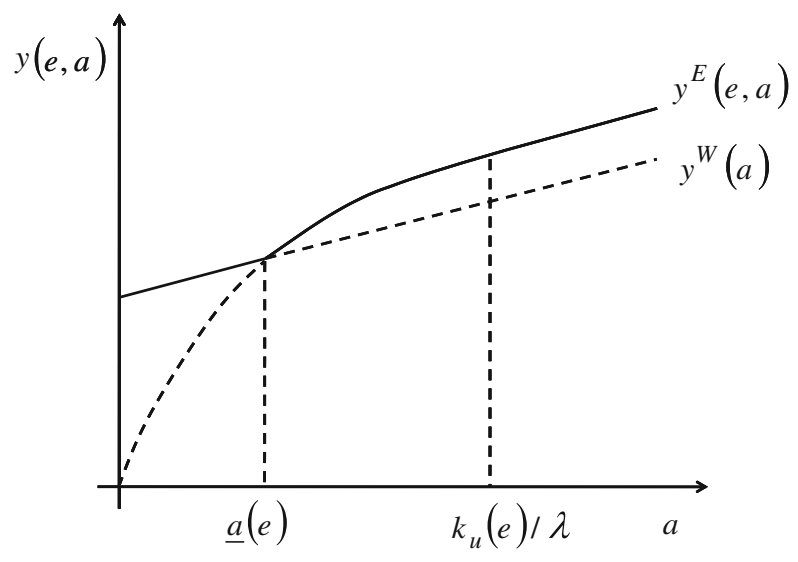

Fig. 1 Technologies available to households 


\subsection{The evolution of individual wealth}

This section reviews a characterization of the evolution of individual wealth derived in Buera (2007). ${ }^{10}$ The main results are: (a) There exists a threshold wealth level, $a_{s}(e)$, such that individuals with initial wealth below the threshold, $a_{0}<a_{s}(e)$, follow a path associated with decreasing wealth, converging to a zero-wealth steady state where they are wage-earners. Meanwhile, households with initial wealth above the threshold, $a_{0} \geq a_{s}(e)$, save to become entrepreneurs and converge to a high-wealth entrepreneurial steady state. (b) The function $a_{s}(e)$ is strictly decreasing in entrepreneurial ability and there exists a minimum ability, $e_{h i g h}$, such that individuals with ability above $e_{\text {high }}$ save to become entrepreneurs regardless of their initial wealth.

Proposition 1 contains the main result of this section: given an ability level $e$, households with low initial wealth will follow a path converging to a zero-wealth worker steady state, and households with high initial wealth will follow a path converging to a high-wealth entrepreneurial steady state. For this result we assume $r<\rho$.

Proposition 1 (Buera 2007) There exists a strictly positive ability level, $e_{\text {low }}$ and a finite ability level, $e_{\text {high }}$ such that:

1. For individuals with low ability, $e \leq e_{\text {low }}$, it is optimal to have low savings and converge to a steady state with zero wealth and low consumption, $(0, w)$, for all levels of initial wealth.

2. For intermediate ability types, $e \in\left(e_{\text {low }}, e_{\text {high }}\right)$, there is a single initial wealth, $a_{s}(e)$, such that individuals starting with wealth level, $a_{s}(e)$, will be indifferent between following a trajectory with low savings that converges to a zero wealth and low consumption steady state, $(0, w)$, or to follow a trajectory with high savings that converges to a steady state with high wealth and consumption, $\left(a_{s s}, c_{s s}\right)$. Agents with initial wealth to the left of $a_{s}(e)$ prefer to follow the trajectory with low savings. The converse holds for agents starting with wealth to the right of $a_{s}(e)$.

3. For individuals with high ability, $e \geq e_{\text {high }}$, it is optimal to have high saving rates and to converge to a high wealth and consumption steady state, $\left(a_{s s}, c_{s s}\right)$, for all levels of initial wealth.

Proof See Buera (2007).

Intuitively, households with low initial wealth require a larger investment in terms of forgone consumption to save up toward the efficient scale. Thus, they prefer to have a lower but smoother consumption profile as wage earners. $k 2$ illustrates the optimal trajectories in the intermediate ability case. ${ }^{11}$ In the case $r=\rho$, a related characterization holds with the only difference that all individuals with low ability, $e \leq e_{l o w}$, and those individuals that start with wealth below $a_{s}(e)$ and $e \in\left(e_{l o w}, e_{h i g h}\right)$, remain with their initial wealth level indefinitely.

\footnotetext{
10 Hopenhayn and Vereshchagina (2007) derive similar results for the discrete time case.

11 For low enough ability $e$ it will the case that $a_{s}>\underline{a}$, implying that there are individuals that start as entrepreneurs, but choose to consume their wealth and eventually become workers.
} 


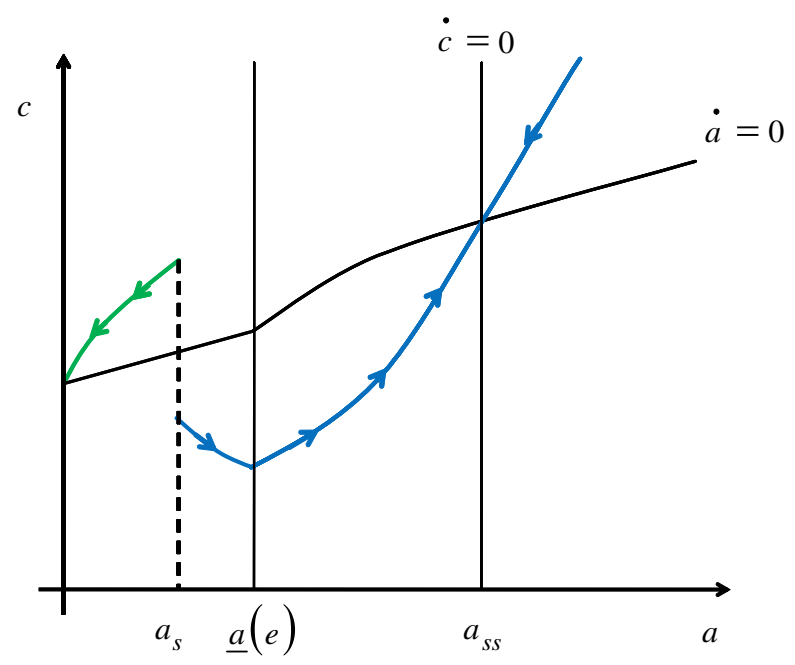

Fig. 2 Optimal trajectories (intermediate ability)

This proposition tells us that the typical policy function for consumption will be discontinuous. For agents with low initial wealth, it is optimal to start with relatively high, but decreasing, consumption. For agents with high initial wealth it is optimal to start with a relatively low, but increasing, consumption. Moreover, there is a unique threshold on initial wealth that divides individuals into these two groups. I refer to this threshold as the poverty trap threshold. The poverty trap threshold is a function of entrepreneurial ability.

This characterization implies the following corollary.

Corollary to Proposition 1 (a) The saving rate of individuals who eventually become entrepreneurs is higher than the saving rate of individuals who remain wage earners. (b) The growth rate of consumption increases after individuals become entrepreneurs.

This suggests two obvious tests for the model that are performed in Sect. 4.

\section{Entry into entrepreneurship and wealth}

Most of the empirical literature on entrepreneurship and borrowing constraints has focused on measuring the effect of wealth on the likelihood that an individual becomes an entrepreneur. A positive relationship is often seen as evidence in favor of the direct effect of borrowing constraints on entrepreneurship. Understandably, many researchers have expressed the concern that wealth and unobservable ability may be positively correlated, making such interpretation problematic. In this section I address these issues.

The likelihood that an individual becomes an entrepreneur as a function of current wealth, conditional on age, $P$ (transition $\mid a, t)$, is a non-monotonic function of wealth. The fraction of individuals that enter entrepreneurship is an increasing function of wealth for low wealth levels, as in a static model (e.g. Evans and Jovanovic 1989), and a decreasing function of wealth for high wealth levels. Moreover, with 


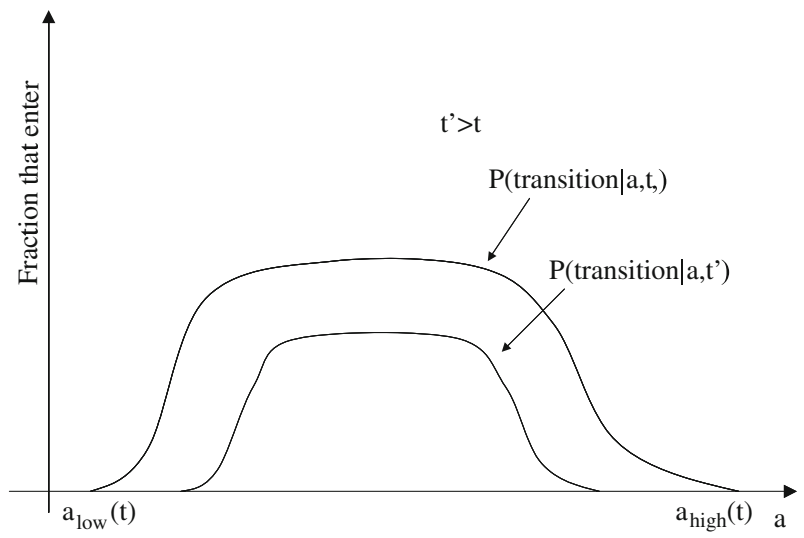

Fig. 3 Transition into entrepreneurship as a function of wealth and age

time the transition probability is compressed from below and above. The intuition for this result is extremely simple. When looking at transitions, we are considering the agents that are working today. But this is a selected sample. In particular, these are individuals that did not find it profitable to start a business by the current period, i.e., they are relatively low ability individuals. Moreover, this selection increases with the wealth of the agents. If somebody is rich and hasn't started a business yet, then he must be a bad entrepreneur. Indeed, if somebody is a worker and has a wealth that is greater than that needed to optimally run the least profitable business among those that would be efficient to operate, then we know that this individual will never be an entrepreneur. Next, I give a formal statement of this result (see $k 3$ for illustration).

Proposition 2 There exists an age $\bar{t}$, an increasing function $a_{\text {low }}(t)$ and a decreasing function $a_{\text {high }}(t)$, satisfying $a_{\text {low }}(t) \leq a_{\text {high }}(t)$, a positive constant $\xi>0$, and neighborhoods $\mathcal{N}\left(a_{\text {high }}(t), \xi\right)$ and $\mathcal{N}\left(a_{\text {low }}(t), \xi\right)$ such that:

1. for all $t<\bar{t}$

$$
P(\text { transition } \mid a, t)=0 \quad \forall a \in\left[0, a_{\text {low }}(t)\right] \cup\left[a_{\text {high }}(t), \infty\right)
$$

and

$$
\begin{aligned}
& P(\text { transition } \mid a, t)>0 \forall a \in \mathcal{N}\left(a_{\text {high }}(t), \xi\right) \text { and } a \leq a_{\text {high }}(t) \\
& P(\text { transition } \mid a, t)>0 \forall a \in \mathcal{N}\left(a_{\text {low }}(t), \xi\right) \text { and } a \geq a_{\text {low }}(t) .
\end{aligned}
$$

2. For all $t \geq \bar{t}$

$$
P(\text { transition } \mid a, t)=0 \text { all } a .
$$

Proof See Appendix.

This proposition suggests a way to obtain information about the importance of borrowing constraints. As previously discussed, workers with enough wealth to optimally 
run the least profitable business (among those that would be efficient to operate) must be so unskilled that they will never be entrepreneurs. This observation suggests a way to obtain a lower bound on the unconstrained scale of businesses, i.e., the unconstrained scale of the least efficient business for a fixed wage and borrowing constraints coefficient, $\lambda$. Indeed, if we were to observe that the decreasing portion of the transition into entrepreneurship occurs at very high wealth levels, we would infer that the entrepreneurial technology is close to linear, or that borrowing constraints are very tight, low $\lambda$, since in this case the optimal scale of the least efficient business will be very large.

Remark 2 The minimum wealth level such that nobody with wealth higher than this amount makes the transition to entrepreneurship provides a lower bound on the unconstrained scale of the least efficient business in operation, i.e. $a_{h i g h}(t) \leq k_{u}(\underline{e})=$ $\underline{a}(\underline{e}) \cdot{ }^{12}$

Next, I consider a straightforward implication of this result.

An important concern of the empirical literature on entrepreneurship and borrowing constraints is to measure the causal effect of wealth on the likelihood that an individual starts a business. It is often believed that the actual correlation between entry into entrepreneurship and wealth overestimates the causal effect (e.g. Holtz-Eakin et al. (1994)). It turns out that in a dynamic model, at high levels of wealth the opposite is true. From proposition 2 we know that, for high wealth levels, wealth close to $a_{h i g h}$, the transition to entrepreneurship as a function of wealth is decreasing. In contrast, the effect of a wealth transfer is always non-negative. Thus, the observed effect of wealth on entrepreneurship underestimates the effect of a wealth transfer. This is the content of the next remark.

Remark 3 For $0<t<\bar{t}$

$$
\begin{aligned}
& \frac{\partial P(\text { transition } \mid a, t, \tilde{a})}{\partial a}<0<\frac{\partial P(\text { transition } \mid a, t, \tilde{a})}{\partial \tilde{a}} \\
& \forall a \in N\left(a_{h i g h}(t), \xi\right) \text { and } a \leq a_{\text {high }}(t),
\end{aligned}
$$

where $\tilde{a}$ corresponds to an exogenous transfer of wealth at time $t$ that individuals expect to be zero with certainty.

We are now ready to study the full set of implications of the dynamic model.

\section{Empirical evidence and structural estimation}

In this section, U.S. data on savings rates, consumption growth of entrepreneurs, and the relationship between entry and wealth are used to evaluate the predictions of the dynamic model and to estimate it using simulated method of moments as described in

\footnotetext{
12 In the case $\lambda>1$ (i.e., we allow borrowing), this inequality becomes $\lambda a_{h i g h}(t) \leq k_{u}(\underline{e})$. A large $a_{\text {high }}(t)$ can be rationalized by a large optimal scale of operations or by a tight borrowing constraint (low $\lambda$ ).
} 
Gourieroux and Monfort (1996). The idea is to choose the parameters of the dynamic model to minimize the distance between a set of statistics describing the behavior of savings rates and entrepreneurial dynamics in the U.S. data and those same statistics calculated from the simulated model. I begin by discussing the main features of the savings rates of entrepreneurs and the dynamics of entrepreneurship in two U.S. datasets.

\subsection{Empirical evidence}

I use a yearly panel for the period 1984-1995 from the Panel Study of Income Dynamics (PSID) with rich information on occupational choice, ownership of businesses, and the wealth of U.S. households; and a quarterly rotating panel (1984-1999) from the Consumer Expenditure Survey (CEX) providing consumption data and information on occupational choice. Since the model provides a theory of the initial transition into entrepreneurship, I estimate the model with data on the savings behavior and the dynamics of entrepreneurship for young households (those that are up to 31 years old). Therefore, unless otherwise noted, all statistics are calculated for households that are up to 31 years old in the initial period. The data used is described in the data Appendix A.

Following the recent literature (see Gentry and Hubbard (2001) and Hurst and Lusardi (2004)), an entrepreneur in the data is identified as someone who reports owning a business. Unfortunately, this information is not available for the CEX. In the case of the CEX, an entrepreneur is identified as someone who reports being self-employed. Whenever it is possible, results are shown for both definitions.

The first and second columns of Table 1 report the main facts regarding the behavior of savings rates and consumption growth of entrepreneurs as measured by the ownership of a business and the self-employed status of the head of the household. ${ }^{13}$ Here I sketch a summary of the data.

- Individuals save more prior to starting a business. Among the young households (age $\leq 31$ ), those that became business owners between periods $t$ and $t+1$ save 7 percentage points more in the previous 5 years (between $t-5$ and $t$ ) than households that neither owned a business in $t$ nor in $t+1$ (see first row of Table 1). Related, individuals becoming business owners between $t-5$ and $t$ save $26 \%$ more between these years than those that do not own businesses between $t-5$ and $t$. This is referred to as the savings rate differential "during entry" in Table $1 .{ }^{14}$

- Business owners have higher saving rates than non-business owners, and their saving rates decrease sharply with age. Households that own a business in $t-5$ and $t$ and are up to 31 years old in period $t-5$ save $26 \%$ more than households

\footnotetext{
13 All the moments are calculated using individual characteristics as controls (sex, marital status, and education of the head). The value of the different moments should therefore be interpreted as the one for a single white male with college education.

14 Although the first is a more appropriate measure of savings in anticipation of entry, it cannot always be calculated in the simulated model since for some parameter values all entrepreneurs enter in less than 5 years.
} 
Table 1 Data and simulated moments (see data appendix for details)

\begin{tabular}{|c|c|c|c|c|}
\hline \multirow[t]{2}{*}{ Moments } & \multicolumn{2}{|l|}{ Data } & \multicolumn{2}{|l|}{ Model } \\
\hline & Business & Self-employed & $\phi^{*}=0.36$ & $\phi=0.70$ \\
\hline \multicolumn{5}{|c|}{$\begin{array}{l}\text { Savings rate differentials of entrepreneurs } \\
\text { vis-à-vis workers }\end{array}$} \\
\hline Prior to entry & $\begin{array}{l}0.07 \\
(0.05)\end{array}$ & $\begin{array}{l}-0.06 \\
(0.05)\end{array}$ & 0.30 & 0.30 \\
\hline During entry* & $\begin{array}{l}0.26 \\
(0.04)\end{array}$ & $\begin{array}{l}0.19 \\
(0.04)\end{array}$ & 0.34 & 0.43 \\
\hline \multicolumn{5}{|l|}{ After entry } \\
\hline Young* & $\begin{array}{l}0.26 \\
(0.08)\end{array}$ & $\begin{array}{l}0.30 \\
(0.05)\end{array}$ & 0.25 & 0.32 \\
\hline Mature* & $\begin{array}{l}0.10 \\
(0.05)\end{array}$ & $\begin{array}{l}0.11 \\
(0.06)\end{array}$ & 0.11 & 0.13 \\
\hline \multicolumn{5}{|c|}{$\begin{array}{l}\text { Consumption growth differential entrepreneurs } \\
\text { vis-à-vis workers }\end{array}$} \\
\hline During entry & - & $\begin{array}{l}0.09 \\
(0.04)\end{array}$ & 0.24 & 0.33 \\
\hline After entry & - & $\begin{array}{l}0.01 \\
(0.03)\end{array}$ & 0.09 & 0.16 \\
\hline
\end{tabular}

The moments that are signaled with "*” are the ones targeted when estimating the model

that neither own a business in $t-5$ nor in $t$. Among mature households (those that are between 32 and 41 years old in $t-5$ ), business owners save just $10 \%$ more than non-business owners.

- Individuals becoming self-employed have higher consumption growth, both relative to workers and to individuals that are already self-employed. The growth in consumption between $t-1$ and $t$ of individuals becoming self-employed between $t-1$ and $t$ is $9 \%$ higher than that of those who are workers in both periods. The consumption growth of households that are already self-employed is not particularly high.

The following fact is illustrated in $k 4$.

- Poor individuals and extremely rich individuals are less likely to start businesses. Among the young, the probability that a household that is not a business owner in period $t-5$ starts a business in period $t$ is mostly constant (around 10\%) for the first 3 wealth to wage ratio quartiles, increases sharply to $20 \%$ for wealth to wage ratios in the 90th to 95th percentiles, and then decreasing for wealth to wage ratios in the top 5 percentiles.

Related datasets and facts have been studied by other authors. Quadrini (1999, 2000), also using the PSID, presents evidence that entrepreneurs, and workers becoming entrepreneurs, are more likely to increase their wealth to income ratios. Using the 1983-1989 panel from the Survey of Consumer Finances, Gentry and Hubbard (2001) 


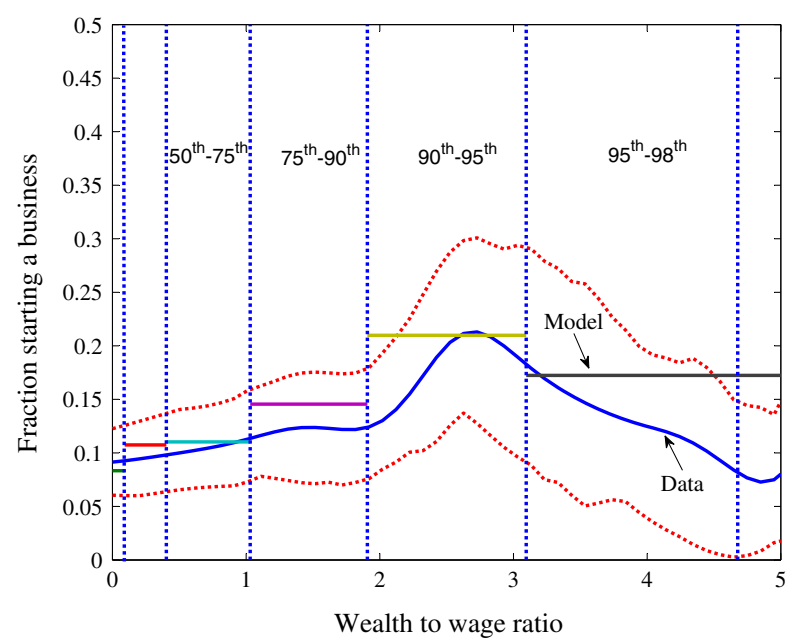

Fig. 4 Wealth to wage ratios and the transition into business ownership, PSID (solid lines) and estimated model (segments), and 5 percent error bands (dotted lines). The relationship in the data corresponds to a semiparametric regression using the method described in Robinson (1988)

report business owners having larger savings rates than non-business owners, and this effect being stronger for younger households as opposed to middle-aged households. They also find that households save more while becoming business owners. In their sample, the median household that becomes a business owner during the 6-year sample period saves 30 percent more than households that never own a business during that time. Unfortunately, given the short SCF panel they cannot study saving behavior in anticipation of the entry decision as is done in the current paper. More in line with my findings on relatively low savings rates in anticipation of entry, Hurst and Lusardi (2004), also using the PSID, find that previous wealth changes are weakly (and even negatively) correlated with future entry decisions. They also study the relationship between wealth and the likelihood of becoming a business owner and find that the positive effect of wealth is stronger for the top percentiles of the wealth distribution. An important difference between the results in Fig. 4 and the evidence in Hurst and Lusardi (2004) is that I measure wealth in relative (to the wage) rather than in absolute terms. $^{15}$

\subsection{Structural estimation}

I first discuss the parametrization of preferences and technologies.

Preferences are assumed to be represented by a standard CES utility function

\footnotetext{
15 Using wealth in relative (to the wage) rather than absolute terms could be sensitive to the measurement of wages. This does not seem to be an important concern as those households that have high levels of relative wealth also have high levels of absolute wealth. For example, the median absolute wealth among the households that are in the top $10 \%$ of relative wealth is 217540 dollars, roughly similar to the wealth of the top 5 percentile of the absolute wealth distribution (241630 dollars).
} 


$$
u(c)=\frac{c^{1-\sigma}}{1-\sigma}
$$

where $\sigma$ is the reciprocal of the intertemporal elasticity of substitution.

Following Lucas (1978), I propose a constant return to scale technology on the entrepreneurial ability, capital, and labor,

$$
\tilde{f}(e, k, n)=e^{v}\left(k^{\alpha} n^{1-\alpha}\right)^{1-v}-\delta k
$$

where $\alpha$ represents the share of payments going to the variable factors, capital and labor, that are paid to capital, and $v$ the share of payments going to the entrepreneur (it is also referred to as the span of control parameter (Lucas 1978)). Note that I only need to specify the reduced form for output net of labor costs, once labor is chosen optimally,

$$
\begin{aligned}
f(e, k) & =\max _{l}\left\{e^{v}\left(k^{\alpha} n^{1-\alpha}\right)^{1-v}-\delta k-\bar{w} n\right\} \\
& =A e^{1-\phi} k^{\phi}-\delta k
\end{aligned}
$$

where $\bar{w}$ is the price of an efficiency unit of labor,

$A=(1-(1-v)(1-\alpha))\left[\frac{(1-v)(1-\alpha)}{\bar{w}}\right]^{\frac{(1-v)(1-\alpha)}{1-(1-v)(1-\alpha)}}$, and $\phi=\frac{(1-v) \alpha}{1-(1-v)(1-\alpha)}$.

Finally, it is convenient to normalize the ability index to correspond to the profits, relative to labor earnings, that an entrepreneur would make if unconstrained,

$$
\tilde{e}=\max _{k}\left\{A \tilde{e}^{1-\phi} k^{\phi}-(r+\delta) k\right\}
$$

When estimating the model I assume individuals live and work for 40 periods. The value of their wealth after they die is assumed to be zero, i.e., there is no bequest motive. As mentioned when introducing the model, the continuous time framework with infinite horizon was chosen to obtain a clearer analytical characterization of the transition probability. When simulating and estimating the model, it is more convenient and natural to work with the discrete and finite horizon version of the theory.

The structure of the model is characterized by two preference parameters, $\sigma$ and $\rho$, one technological parameter, $\phi$, the borrowing constraint coefficient, $\lambda$, and the distribution of ability, $g(\tilde{e})$. To close the model, the interest rate, $r$, and initial distribution of wealth, $h\left(a_{0}\right)$, also need to be specified. The parameters are chosen using a combination of calibration and structural estimation. I choose values for the preference parameters, the interest rate and the depreciation rate following the standard practices: $\sigma=1.5, \rho=r=0.02$ and $\delta=0.08$. $^{16}$ The distribution of initial wealth relative to wages is assumed to be independent of ability and is chosen to correspond to the distribution of wealth to income ratios of non-business owners that are up to 26 years old in the PSID. This leaves the technology parameter, $\phi$, the borrowing constraint

\footnotetext{
16 Notice that since individuals phase a finite horizon, $r=\rho$ does not correspond to the case of a constant consumption path.
} 
coefficient, $\lambda$, and the distribution of ability to be jointly estimated by minimizing the distance between the moments in the data and the moments in the model. The details of the algorithm are described in the Appendix. A heuristic discussion of the identification of the model follows.

There are eight parameters $(\phi, \lambda$, and six probabilities describing the ability distribution) that are estimated by matching nine moments (three moments related to the savings behavior of entrepreneurs vis-à-vis workers and the entry rates for six wealth to income groups). ${ }^{17}$ Given values for $\phi$ and $\lambda$, the distribution of ability is identified from the fraction of entrants at each wealth group. To do this mapping, we need to use the information on the initial distribution of wealth and the dynamics of wealth implied by the model. Obviously, the shape of the distribution of ability for ability levels such that individuals never transition into entrepreneurship cannot be identified, i.e., for $\tilde{e}$ such that $\underline{a}(\tilde{e})<a_{s}(\tilde{e})$. The parameters $\phi$ and $\lambda$ are then identified by matching the relationship between wealth to wage ratios and entry for large values of the wealth to wage ratios as suggested by Remark 2 , and the saving rate differential. In particular, I use information on how quickly business owners converge to the steady state scale of their businesses, as measured by how quickly their saving rates decrease over time.

The first column of Table 2 reports the parameter estimates and their standard errors. An economy where entrepreneurs face strong decreasing returns to scale, $\phi=0.36$, and tight borrowing constraints, $\lambda=1.01$, best fits the data shown in the first column of Table 1 . The distribution of ability turned out to be bimodal with $40 \%$ of the profitable entrepreneurs (those with relative ability $\frac{\tilde{e}}{w}>1$ ) having low returns (they could earn 5\% more income as unconstrained entrepreneurs) and 30\% facing large returns to entrepreneurship (they could earn three times as much income as unconstrained entrepreneurs). Of the individuals that could be productive entrepreneurs, $\tilde{e}>1$, on average $40 \%$ are workers. Most of these, $94 \%$, will remain workers as they prefer not to save and finance a business that is not that productive. ${ }^{18}$ Finally, the fraction of individuals with ability $\tilde{e}=1$ (unprofitable entrepreneur) is 0.24 , implying a counterfactually high fraction of entrepreneurs of $46 \%$. This last fact is an artifact of not modelling exit and reentry of businesses.

The estimate for $\phi$ is in line with the previous estimates by Evans and Jovanovic (1989), also using micro data for the U.S., while the estimate for $\lambda$ is relatively low. The second column of Table 2 reports the estimate for the borrowing constraint and the distribution of talent when the curvature parameter is constrained to take a larger value, $\phi=0.7$. To fit the data, a less tight borrowing constraint is needed, $\lambda=4.9$.

$k 4$ and the third column of Table 1 report the moments from the simulated model at the estimated parameters. The model does a good job of fitting the relationship between the transition into business ownership and wealth, especially the fact that "only for households at the top of the wealth distribution is there a strong and positive relationship between household wealth and business entry" (see Hurst and Lusardi (2004)). Savings rates of entrepreneurs, both young and mature, are matched but the

\footnotetext{
17 The wealth to income groups are: the bottom 25 th percentile, 25 th to 50 th percentile, 50 th to 75 th percentile, 75 th to 90 th percentile, 90 th to 95 th percentile, and the top 5th percentile.

18 In the estimated model only individuals with $\tilde{e}=1.05$ are in a poverty trap and do not save to become entrepreneurs.
} 
Table 2 Parameter estimates

\begin{tabular}{cll}
\hline Parameters & Estimate & \\
\cline { 2 - 3 } & Unconstrained & Constrained \\
\hline Technology, $\phi$ & 0.36 & 0.70 \\
Borrowing constraint, $\lambda$ & $(0.01)$ & - \\
& 1.01 & 4.90 \\
Probability $(\tilde{e} \mid \tilde{e}>1)(\%$ entrepreneurs $)$ & $(0.03)$ & $(0.04)$ \\
$\tilde{e}=1.05$ & & $0.39(0.04)$ \\
1.20 & $0.39(0.04)$ & $0.00(0.79)$ \\
1.50 & $0.02(0.83)$ & $0.05(0.89)$ \\
3.00 & $0.23(0.95)$ & $0.37(0.97)$ \\
5.00 & $0.32(0.99)$ & $0.00(0.98)$ \\
10.00 & $0.05(0.99)$ & $0.20(0.99)$ \\
Average welfare costs $(\%)$ & $0.00(0.99)$ & 8.84 \\
$\chi^{2}(p$-value, $d f)$ & 6.24 & $40.26(0.001,3)$
\end{tabular}

The probability that $e=1$ is 0.24

model substantially overpredicts the savings rates prior to entry. The same is true for the growth rate of the consumption of entrepreneurs. One the one hand, the behavior of savings rates and consumption growth suggest that borrowing constraints are not very important. But the relationship between wealth and the transition into entrepreneurship suggests the opposite conclusion. The decreasing part of the transition into entrepreneurship happens for very large wealth to wage ratios, implying that the unconstrained scale of businesses is very large and, therefore, this suggests that the entrepreneurial technology is relatively linear. The estimation is the result of a compromise between these sets of moments. ${ }^{19}$ This is a clearly imperfect compromise, as is suggested by the rejection of the model by the over-indentification test at the bottom of Table 2 .

The welfare costs of borrowing constraints are large (see last row of Tables 2 and 3 ). Welfare costs are calculated as the fraction by which the path of consumption must be increased to make an individual indifferent between living in the economy with no credit and in the economy with perfect capital markets. These are ex-ante welfare costs, i.e., the welfare costs of an individual before knowing his or her draw from the estimated distribution of ability and wealth. For the median among the productive entrepreneurs (individuals with $\tilde{e}>1$ ) welfare costs amount to $22 \%$ of lifetime consumption. The average welfare cost for the economy is $6 \%$ of lifetime consumption (9\% if $\phi=0.7) .{ }^{20}$ But, because there are strong decreasing returns to scale, most indi-

\footnotetext{
19 If the curvature parameter were to be constrained to take a larger value, $\phi=0.7$, the model would imply a substantially larger saving rate differential for entrepreneurs vis-à-vis workers. This would be particularly true for younger businesses (see column 4 in Table 1). The fit of the model in terms of the relationship between entry and wealth, Fig. 1, is almost identical.

20 When calculating the average welfare cost, I force the distribution of ability to match the fraction of entrepreneurs in the data. This is done by shifting the mass of the ability distribution from ability values
} 
Table 3 Welfare costs by ability (rows) and initial wealth (columns) measured as a fraction of lifetime consumption $(\%)$

\begin{tabular}{lllll}
\hline Ability & Wealth & & & \\
\cline { 2 - 5 } & Zero wealth & $\begin{array}{l}\text { 50th perc. } \\
\text { wealth/wage }\end{array}$ & $\begin{array}{l}\text { 75th perc. } \\
\text { wealth/wage }\end{array}$ & $\begin{array}{l}\text { 90th perc. } \\
\text { wealth/wage }\end{array}$ \\
\hline 1.05 & 5.00 & 4.94 & 4.86 & 4.71 \\
1.20 & 16.12 & 14.99 & 13.35 & 9.81 \\
1.50 & 24.48 & 22.07 & 18.62 & 12.11 \\
3.00 & 40.96 & 34.42 & 26.20 & 18.62 \\
5.00 & 52.08 & 39.10 & 31.02 & 23.52 \\
10.00 & 69.64 & 45.38 & 37.42 & 30.09 \\
\hline
\end{tabular}

viduals can overcome borrowing constraints by internally financing their businesses. This is especially true for very able individuals. In the same direction, the size and economic significance of poverty traps are low. Only individuals that would increase their income by $5 \%$ decide not to save to start a business (12\% of the population falls in this category).

These welfare costs are mainly due to undercapitalized entrepreneurs (intensive margin) rather than profitable entrepreneurs that cannot enter or delay their entry (extensive margin). For example, if individuals that are delaying their entry because they need more wealth to run businesses at a profitable scale were forced to remain workers forever, the average welfare costs would increase by one percentage point, only $15 \%$ of the total welfare costs.

\section{Conclusion}

Does wealth beget wealth and entrepreneurship, or is entrepreneurship mainly determined by an individual's ability? This paper evaluates conventional tests of the existence of financial constraints to entry into entrepreneurship. I show that in a dynamic model, the existence of financial constraints to the creation of business implies a nonmonotonic relationship between wealth and entry into entrepreneurship: the probability of becoming an entrepreneur as a function of wealth is increasing for low wealth levels - as predicted by standard static models — but it is decreasing for higher wealth levels (Figs. 3, 4).

U.S. data are used to study the qualitative and quantitative predictions of the dynamic model. Consistent with the predictions of the theory, the relationship between entry into entrepreneurship and wealth is non-monotonic, entering entrepreneurs exhibit particularly large savings, and the consumption growth of entrepreneurs tends to increase after entry. The welfare costs of borrowing constraints are found to be sig-

Footnote 20 continued

with $e>1$ to values with $e=1$, in a proportional way so that the distribution of ability conditional on $e>1$ is not affected (and therefore not affecting the shape of the transition function (see Fig. 2)). 
nificant, around $6 \%$ of lifetime consumption, and are mainly due to undercapitalized entrepreneurs (intensive margin), rather than to able people not starting businesses (extensive margin).

Open Access This article is distributed under the terms of the Creative Commons Attribution Noncommercial License which permits any noncommercial use, distribution, and reproduction in any medium, provided the original author(s) and source are credited.

\section{Appendix A: Data appendix}

I use a yearly panel for the period 1984-1995 from the Panel Study of Income Dynamics (PSID) with rich information on occupational choices, ownership of businesses and the wealth of U.S. households; and a quarterly rotating panel (1984-1999) from the Consumer Expenditure Survey (CEX) providing consumption data and information on occupational choices.

In the case of the PSID, I create a 7-year panel pooling the households in the 1984-1990 and 1989-1995 samples. This gives a panel with two observations for wealth (1984 and 1989 in the 1984-1990 subsample, 1989 and 1994 in the 19891995 subsample), and yearly observations on the ownership of businesses and income. Using the pooled panel, I construct savings rates between the first and the fifth year, saving $s_{1-5}=\frac{\text { wealt }_{5}-\text { wealt }_{1}}{\sum_{t=1}^{5} \text { income }_{t}}$, wealth to income ratios $=\frac{\text { wealth }_{t}}{\text { income }_{t}}$ (the relevant measure of wealth in the model) and business ownership histories. "Wealth" corresponds to the sum of net equity in a main home, other real estate, vehicles, farm/business, stocks, savings accounts and other assets, less debt; "income" equals total family money income plus food stamps minus federal income taxes paid; and business ownership status is determined by the question "Do you (or anyone in your family living there) own part or all of a farm or business?" For comparison purposes, I also use information about the self-employment status of the head of the household as an alternative proxy for entrepreneurship.

I restrict the sample to the households that are at least 22 and at most 31 years old in the first period, that are working in the 1,2,6 and 7th periods (these are the periods for which business ownership information is used) and I drop the observations with savings rates below and above the 1st and 99th percentiles respectively. These restrictions leave 5,354 observations that are used to calculate the moments reported in Table 1.

In the case of the CEX I use the quarterly interview component for the 19841999 period. From this dataset I use information on non-durable consumption, selfemployed status of the head of the household, and demographic characteristics. After applying restrictions similar to those applied to the PSID sample, 5,545 observations of households that are up to 31 years old are left to calculate the moments reported in Table 1.

\section{Appendix B: Algorithm}

Given values for the preferences and technology parameters $(\sigma, \rho, \phi, \delta)$, the borrowing constraint coefficient $(\lambda)$, and the interest rate $(r)$, the individual decision problem is solved for each ability level in the ability grid, $e=\{1,1.05,1.1,1.2,1.5,2,3,5,7,10\}$ 
(we only allow 7 ability levels to be assigned strictly positive probability), by backward induction from the last period, $T=40$. Given the policy functions and 10,000 values for the initial wealth drawn from the distribution of wealth to income ratio of non-business owners that are up to 26 years old in the PSID, 10,000 histories are generated for each value of ability, $\left\{x_{t}(e)\right\}_{t=1}^{T}$. The initial wealth to income ratio takes values on the grid $a_{0}=\{0,0.17,0.49,1,1.84,2.87,8.03\}$ with probabilities $h\left(a_{0}\right)=\{0.25,0.25,0.25,0.15,0.05,0.03,0.02\}$. Then, by stacking the data for individuals at different ages I obtained a simulated (unbalanced) panel of 400,000 observations (10,000 40-year histories, $\left\{x_{t}(e)\right\}_{t=1}^{T}, 10,00039$-year histories, $\left.\left\{x_{t}(e)\right\}_{t=2}^{T}, \ldots\right)$ that is used to calculate the statistics for each value of ability. Averaging over the distribution of ability, a vector of dimension 7, produces aggregate statistics for the model. The algorithm then searches over values of the returns to scale parameter, $\phi$, the borrowing constraint coefficient, $\lambda$, and the distribution of ability to minimize the weighted distance between the statistics calculated using the PSID data and the data from the simulated model. The weights are given by the inverse of the covariance matrix of the moments from the PSID data. The moments that are targeted are: 1) the savings rate differential of entrepreneurs vis-à-vis workers during entry (0.26), i.e., mean saving rates (between $t$ and $t+5$ ) of households becoming business owners from $t$ to $t+5$ minus that of those not owning businesses in $t$ or $t+5 ; 2$ ) the savings rate differential of young entrepreneurs vis-à-vis workers after entry (0.26), ie., mean saving rates (between $t$ and $t+5$ ) of young households (age less or equal to 31) owning businesses in $t$ minus that of those young individuals not owning businesses in $t$ or $t+5 ; 3$ ) the savings rate differential of mature entrepreneurs (in between 31 and 41 years old) vis-à-vis mature workers after entry $(0.10), 4)$ the fraction of workers becoming entrepreneurs at six intervals of the wealth to income distribution ( $0-25$ th, 25-50th, 50-75th and 90th percentiles). The fraction of entrants are .08, .10, .11,.13, .19 , and .17. Asymptotic standard errors computed using the Hessian of the criterion function are reported.

An important simplification is introduced by the fact that ability is fixed over the life of an individual. For given values of $\phi$ and $\lambda$, a gradient based method (matlab routine fmincon.m) is used to minimize over the distribution of ability subject to the constraint that at most six ability values get to be assigned a positive probability. Then, grid search is used to minimize over $\phi$ and $\lambda$.

\section{Appendix C: Proof of the results in the paper}

Assumption A.1: The policy function, $a\left(a_{0}, t, e\right)$, is strictly increasing and continuous in the entrepreneurial ability, $e$, for $a_{0} \geq a_{s}(e)$.

This is a natural assumption. It requires that present consumption does not increase too much when ability increases. In terms of assumptions about preferences, it requires that the preferences between consumption today and tomorrow are not too biased toward present consumption. For example, it will be true in a two period model if preferences are homothetic.

Proof of Proposition 2. The transition probability conditional on wealth, $a$, and age, $t$, is given by the integral over all agents with ability high enough such that they find 
it profitable to start a business by $t+\Delta, e>\underline{\underline{a}}^{-1}(a+\tilde{a}, \Delta)$, but not so high for them to be already entrepreneurs, $e<\underline{a}^{-1}(a)$. Where $\underline{\underline{a}}(e, \Delta)$ solves the equation $a(\underline{\underline{a}}(e, \Delta), \Delta, e)=\underline{a}(e)$. Formally

$$
P(\text { transition } \mid a, t, \tilde{a}, \Delta)=\frac{\iint_{e \in \mathcal{E}^{w}(a, t), e>\underline{\underline{a}}^{-1}(a+\tilde{a}, \Delta)} g(e) h\left(a_{0}(a, t, e)\right) d e}{1-P(\text { entrepreneur } \mid a, t)}
$$

where $g(e)$ is the density of the distribution of ability, $h(a)$ the density of the distribution of wealth, and $\mathcal{E}^{w}(a, t)$ is the support of ability conditional on wealth $a$, age $t$ and currently being one of the workers that will eventually become entrepreneurs, $\mathcal{E}^{w}(a, t)=\left\{e \in R_{+}: \exists a_{0}\right.$ for which $a\left(a_{0}, t, e\right)=a, e<\underline{a}^{-1}(a)$ and $\left.e \geq a_{s}^{-1}(a)\right\}$. Then, to prove this result we need to characterize the lowest and highest wealth levels, $a_{\text {low }}(t)$ and $a_{\text {high }}(t)$, such that this set is non-empty. We assume that initially wealth and ability are independent. ${ }^{21}$

That there exists an increasing function $a_{\text {low }}(t)$ such that for $a<a_{\text {low }}(t)$ the set $\mathcal{E}^{w}(a, t)$ is empty follows trivially from the fact that the wealth of individuals that will eventually become entrepreneurs increases over time and that $a_{0} \geq 0$.

The function $a_{h i g h}(t)=\underline{a}\left(e_{\min }(t)\right)$ where $e_{\min }(t)=\inf \left\{e \in\left[e_{\text {low }}, \infty\right]:\right.$ $\left.a\left(a_{s}(e), t, e\right)=\underline{a}(e)\right\}$. Note that $e_{\min }(t)$ is a strictly increasing function of $t$ since for $e$ close to $e_{\text {low }}\left(a_{s}\left(e_{\text {low }}\right)=\underline{a}\left(e_{\text {low }}\right)\right)$, we know that $a\left(a_{s}(e), t, e\right)>\underline{a}(e)$ and, by continuity, we know that for the minimum root of the equation $a\left(a_{s}(e), t, e\right)=\underline{a}(e)$ the function $a\left(a_{s}(e), t, e\right)$ is decreasing and crosses the function $a_{s}(e)$ from below. Thus, the function $a_{h i g h}(t)$ is decreasing since it is the composite of a strictly decreasing function with an increasing function.

The maximum age such that the set $\mathcal{E}^{w}(a, t)$ is non-empty for some wealth level is defined by

$$
\bar{t}=\inf \left\{t \in R_{++}: a\left(a_{s}(e), t, e\right) \geq \underline{a}(e) \quad \forall e \geq e_{\min }\right\}
$$

Age $\bar{t}$ is finite since $\underline{a}(e)<a_{s s}(e) \forall e \geq e_{\min }$.

\section{References}

Buera, F.: Persistency of Poverty, Financial Frictions, and Entrepreneurship. mimeo Northwestern University (2007)

Cagetti, M., De Nardi, M.: Taxation, Entrepreneurship, and Wealth. Staff Report 340, Federal Reserve Bank of Minneapolis (2004)

Cagetti, M., De Nardi, M.: Entrepreneurship, Frictions, and Wealth. WP 2005-09, Federal Reserve Bank of Chicago (2005)

Evans, D., Jovanovic, B.: An estimated model of entrepreneurial choice under liquidity constraints. J Polit Econ 97, 808-27 (1989)

Evans, D., Leighton, L.: Some empirical aspects of entrepreneurship. Am Econ Rev 79, 519-35 (1989)

\footnotetext{
21 This assumption is without loss of generality. The argument in this proof only relies on properties of $\mathcal{E}^{w}(a, t)$, the support of ability conditional on wealth $a$, age $t$, and currently being one of the workers that will eventually become entrepreneurs.
} 
Gentry, W., Hubbard, G.: Entrepreneurship and Saving. mimeo, Columbia Business School (2001)

Gourieroux, C., Monfort, A.: Simulation-Based Econometric Methods. New York: Oxford University Press (1996)

Holtz-Eakin, D., Joulfaian, D., Rosen, H.: Entrepreneurial decisions and liquidity constraints. Rand J Econ 23, 340-347 (1994)

Hopenhayn H., Vereshchagina G.: Risk Taking by Entrepreneurs. mimeo, University of California at Los Angeles (2007)

Hurst, E., Lusardi, A.: Liquidity constraints, wealth accumulation and entrepreneurship. J Polit Econ 112(2), (2004)

Li, W.: Entrepreneurship and government subsidies: a general equilibrium analysis. J Econ Dyn Control 26, 1815-1844 (2002)

Lucas, R.E.: On the size distribution of business firms. Bell J Econ 9(2), 508-523 (1978)

Meh, C.: Entrepreneurship, wealth inequality and taxation. Rev Econ Dyn 8(3), 688-719 (2005)

Paulson, A., Townsend, R.: Entrepreneurship and financial constraints in Thailand. J Corp Finance 10(2), 229-262 (2004)

Quadrini, V.: The importance of entrepreneurship for wealth concentration and mobility. Rev Income Wealth 45, 1-19 (1999)

Quadrini, V.: Entrepreneurship, saving and social mobility. Rev Econ Dyn 3, 1-40 (2000)

Robinson, P.M.: Root-N consistent semiparametric regression. Econometrica 56, 931-954 (1988) 